\title{
CARGAS DE TRABALHO E DESGASTES DOS TRABALHADORES DE ENFERMAGEM EM SERVIÇOS DE MEDICINA NUCLEAR DO BRASIL
}

\author{
WORKLOADS AND EXHAUSTION AMONG NURSING WORKERS IN \\ NUCLEAR MEDICINE SERVICES IN BRAZIL
}

\author{
CARGAS DE TRABAJO Y DESGASTE DE LOS TRABAJADORES DE \\ ENFERMERÍA EN SERVICIOS DE MEDICINA NUCLEAR EN BRASIL
}

\author{
Juliana Almeida Coelho De Melo* \\ Francine Lima GelbCKe** \\ Felipa Rafaela Amadagi*** \\ ANDrea HuHn ${ }^{* * * *}$ \\ Charlene Da Silva*****
}

\begin{abstract}
RESUMO
Objetivo: Identificar as cargas de trabalho geradoras de desgastes em trabalhadores de enfermagem em dois Serviços de Medicina Nuclear (SMN) localizados na regiáo sul do Brasil. Material e Método: Trata-se de pesquisa qualitativa, pautada na Psicodinâmica do Trabalho, que investigou 12 trabalhadores de enfermagem atuantes em dois SMN, um público e um privado. Os dados foram organizados com o auxílio do software QualiQuantSoft ${ }^{\circ}$ e interpretados por meio da análise do discurso do sujeito coletivo. Resultados: Os trabalhadores pesquisados estão expostos às cargas de trabalho de materialidade interna e externa. As cargas de trabalho biológicas, físicas, mecânicas, fisiológicas e psíquicas foram fortemente representadas nos discursos dos trabalhadores. Essas cargas são responsáveis por desgastes que se manifestam em dores lombares, problemas osteoarticulares, fadiga e desgastes psíquicos. Os desgastes evidenciados estão diretamente relacionados à natureza e intensidade das cargas de trabalho no cotidiano do profissional. Conclusão: Na medicina nuclear observa-se a sobreposição das cargas de trabalho inerentes a organizaçáo e as especificidades da atividade laboral. As cargas de trabalho se manifestam, principalmente, quanto ao uso da radiação ionizante, sendo que os desgastes impactam no corpo do trabalhador em manifestaçóes físicas e psíquicas. A enfermagem, enquanto categoria, deve ser empoderada
\end{abstract}

\footnotetext{
*Doutora em Enfermagem. Docente do Instituto Federal de Educação Ciência e Tecnologia de Santa Catarina (IFSC), Florianópolis, Brasil. ORCID: https://orcid.org/0000-0003-2217-9649 Email: julianarad@gmail.com Autor correspondente.

${ }^{* *}$ Doutora em Enfermagem. Docente da Universidade Federal de Santa Catarina (UFSC), Florianópolis, Brasil. ORCID: https://orcid.org/0000-0003-3742-5814 Email: fgelbcke@nfr.ufsc.br

***Doutora em Enfermagem. Docente da Universidade Federal de Santa Catarina (UFSC), Florianópolis, Brasil. ORCID: https://orcid.org/0000-0003-1480-1231 Email: felipa.amadigi@ufsc.br

****Doutora em Enfermagem. Docente do Instituto Federal de Educação Ciência e Tecnologia de Santa Catarina (IFSC), Florianópolis, Brasil. ORCID: https://orcid.org/0000-0002-4348-9374 Email: andreahuhn@ifsc.edu.br

*****Mestre em Proteção Radiológica. Docente do Instituto Federal de Santa Catarina, Florianópolis, Brasil, ORCID: https:// orcid.org/0000-0003-0761-4358 Email: charlene.silva@ifsc.edu.br
} 
de forma mais assertiva dessa especialidade através de educação continuada e pesquisas sobre a temática, pois trata-se de uma área de atuaçáo em expansão para esses profissionais.

Palavras-chave: Saúde do Trabalhador; Carga de Trabalho; Medicina Nuclear; Desgaste Profissional; Enfermagem Radiológica.

\begin{abstract}
Objective: To identify the workloads that generate exhaustion in nursing workers of two Nuclear Medicine Services (NMS) located in southern Brazil. Material and Method: Qualitative research, based on the Psychodynamics of Work, which focused on 12 nursing workers at two NMS, one public and one private. The data were organized using the QualiQuantSoft ${ }^{\circledast}$ software and interpreted through the analysis of the discourse of the collective subject. Results: The surveyed workers are exposed to workloads of internal and external materiality. The biological, physical, mechanical, physiological and psychological workloads were strongly represented in the workers' discourses. These loads are responsible for exhaustion that is manifested in low back pain, osteoarticular problems, fatigue and psychological stress. The stress shown is directly related to the nature and intensity of workloads in the professional's daily life. Conclusion: In the field of nuclear medicine, there is an overlapping of workloads that is inherent to the organization and specificities of the work activity. Workloads are manifested mainly in the use of ionizing radiation, and the resulting exhaustion affects the worker's body with physical and psychological symptoms. Nursing, as a category, should be more assertively involved in this specialty through continuing education and research on the subject, as it is an expanding area of activity for nursing professionals.
\end{abstract}

Key words: Occupational Health; Workload; Nuclear Medicine; Professional Exhaustion; Radiological Nursing.

\title{
RESUMEN
}

Objetivo: Identificar las cargas de trabajo que generan desgaste en el personal de enfermería de dos Servicios de Medicina Nuclear (SMN) ubicados al sur de Brasil. Material y Método: Se trata de una investigación cualitativa, basada en la Psicodinámica del Trabajo, que investigó a 12 trabajadores de enfermería que trabajan en dos SMN, uno público y otro privado. Los datos fueron organizados con la ayuda del software QualiQuantSoft ${ }^{\odot}$ e interpretados a través del análisis del discurso del sujeto colectivo. Resultados: Los trabajadores encuestados están expuestos a cargas de trabajo de materialidad interna y externa. Las cargas de trabajo biológicas, físicas, mecánicas, fisiológicas y psicológicas estuvieron fuertemente representadas en los discursos de los trabajadores. Estas cargas son las responsables del desgaste que se manifiesta en lumbalgia, problemas osteoarticulares, fatiga y desgaste psicológico. El estrés encontrado está directamente relacionado con la naturaleza e intensidad de las cargas de trabajo en la vida diaria del profesional. Conclusión: En medicina nuclear existe una superposición de cargas de trabajo inherentes a la organización y especificidades de la actividad laboral. Las cargas de trabajo se manifiestan, principalmente, en el uso de radiaciones ionizantes y el desgaste impacta en el cuerpo del trabajador con manifestaciones físicas y psicológicas. Enfermería, como categoría, debe empoderarse de manera más asertiva en esta especialidad a través de la educación continua y la investigación sobre el tema, por ser, para estos profesionales, un área de actividad en expansión.

Palabras clave: Salud laboral; Carga de trabajo; Medicina Nuclear; Agotamiento Profesional; Enfermería Radiológica.

Fecha de recepción: 02/06/2020

Fecha de aceptación: 12/11/2020 


\section{INTRODUÇÁO}

No Brasil, o avanço tecnológico veio acompanhado de modelos de produçáo pautados na competitividade, produtividade e lucro, o que reflete em mudanças nos modos de organizaçáo e gestão que, por consequência, impactam diretamente na saúde do trabalhador ${ }^{(1)}$. A maneira como o trabalho é desenvolvido e organizado impóe ao profissional diferentes cargas de trabalho que podem potencializar desgastes à saúde física e mental ${ }^{(2)}$. Nos serviços de saúde, a equipe de enfermagem está exposta às diferentes cargas de trabalho que, somadas ao convívio constante com situaçóes de morte, sofrimento e dor, impactam diretamente em sua saúde, interferindo na sua relação com o trabalho, acometendo suas condiçóes de vida e com isso, potencializando desgastes ${ }^{(3-5)}$.

Entre os estabelecimentos de saúde, destaca-se o Serviço de Medicina Nuclear (SMN) que utiliza radionuclídeos, emissores de radiação ionizante, com propósito terapêutico ${ }^{(6)}$ e diagnóstico ${ }^{(7)}$. O SMN deve ser constituído por um número mínimo de profissionais de nível técnico ou superior qualificados $^{(8)}$ entre os quais está o profissional da enfermagem. $\mathrm{O}$ processo de trabalho da equipe de enfermagem no Brasil, acontece na administração do radionuclídeo ligado a um fármaco (radiofármaco), e na assistência prestada aos usuários ao longo do procedimento. As potenciais ameaças à saúde do trabalhador, referem-se ao contato próximo e prolongado com o usuário que é o emissor de radiação ou, na contaminação pelo radiofármaco, no momento da aplicação no usuário ${ }^{(9)}$.

As cargas de trabalho estão diretamente relacionadas às especificidades do processo de trabalho, no caso dos SMN, somam-se as cargas de trabalho intrínsecas a natureza do trabalho da enfermagem às demandas específicas dessa especialidade. Cita-se sobretudo à exposição à radiação, contaminação e mudanças necessárias à assistência, onde realiza-se uma assistência mais rápida e fisicamente afastada do usuário que recebe os cuidados, em função das doses de radiação ${ }^{(10)}$.

O conceito de cargas de trabalho discutidos no Brasil ${ }^{(10-13)}$ está além do tempo dispendido no trabalho e está relacionado a fatores organizacionais, condiçóes, natureza e processos de trabalho ${ }^{(4)}$. As cargas de trabalho podem ser compreendidas como a relação dinâmica entre os elementos do trabalho e o corpo do trabalhador. As adaptaçôes geradas em resposta a esse processo se traduzem em desgastes no trabalhador e dependem das capacidades biológicas e psíquica deste ${ }^{(14)}$. Os trabalhadores de enfermagem representam uma das maiores forças de trabalho nas instituiçôes de saúde e pela característica do trabalho realizado estão expostos às diferentes cargas de trabalho ${ }^{(4,5,11)}$.

A enfermagem possui uma vasta área de atuação em diferentes contextos de assistência e especialidades, logo, as cargas de trabalho estão diretamente relacionadas às especificidades do processo de trabalho. Ao trabalhar em SMN, somam-se as cargas de trabalho intrínsecas a natureza do trabalho da enfermagem às demandas específicas dessa especialidade, principalmente quanto à exposição à radiação, contaminação e mudanças necessárias à assistência ao usuário, realizando uma assistência mais rápida e fisicamente mais afastada do usuário que recebe os cuidados, em função das doses de radiação ${ }^{(10)}$.

Nesse sentido, é importante que os profissionais de enfermagem em SMN reconheçam as cargas de trabalho a que estáo expostos. Os desgastes são proporcionais às cargas de trabalho que atuam sobre seu corpo $^{(5)}$, e quanto maior o desgaste maior o comprometimento da organização, da assistência prestada e da saúde do trabalhador. O trabalhador de enfermagem precisa compreender as singularidades do processo de trabalho em SMN para minimizar os desgastes. Assim, objetivouse identificar as cargas de trabalho geradoras de desgastes em trabalhadores de enfermagem em SMN.

\section{MATERIAL E MÉTODO}

A pesquisa foi balizada pela ferramenta qualitativa COREQ. Consiste em um estudo descritivo, conduzido pela Psicodinâmica do Trabalho (PT) de Christophe Dejours ${ }^{(2)}$ que possibilita investigar cenários de trabalho com ênfase nos aspectos qualitativos $^{(15)}$. Essa abordagem teórica privilegia a compreensão das relaçóes do trabalhador com o trabalho, bem como todos os aspectos subjetivos que permeiam essa relação ${ }^{(2)}$.

A pesquisa foi aprovada no Comitê de Ética e Pesquisa com Seres Humanos (código: 1.147.328). $\mathrm{O}$ estudo ocorreu em dois $\mathrm{SMN}$, um público e 
um privado, localizados na região sul do Brasil, no período de fevereiro 2015 a janeiro de 2016. A coleta de dados foi executada por meio de observação não participante, entrevistas individuais e coletivas de forma a caracterizar a triangulação dos dados por três instrumentos, com objetivo de compreender os processos do trabalho em enfermagem de forma articulada com a Psicodinâmica do Trabalho. Como critério de seleçáo dos sujeitos da pesquisa adotouse: profissionais da enfermagem atuantes no SMN. A abordagem dos participantes foi realizada em duas reuniôes, em ambos os serviços, na oportunidade foi elucidado a metodologia da pesquisa e assinado o Termo de Consentimento Livre e Esclarecido.

Os participantes da pesquisa contemplou todo o universo de trabalhadores de enfermagem atuantes em SMN dos locais pesquisados. Caracterizando, desse modo, um recrutamento por conveniência de 12 profissionais, ou seja, todos os profissionais de ambos os serviços constituíram os participantes do estudo. Dentre esses trabalhadores havia 4 enfermeiros (2 em cada serviço) e 8 técnicos em enfermagem ( 4 em cada serviço), formando o coletivo de trabalhadores ad hoc. Dejours ${ }^{(2)}$ utiliza essa nomenclatura, pois em PT o foco não é quem é o porta voz da situação, é a situação relatada, que deve ser debatida e acolhida ${ }^{(16)}$. A amostra corresponde a aproximadamente 50\% da força de trabalho da enfermagem em SMN ${ }^{(17)}$ da regiáo. Portanto, infere-se que o resultado da pesquisa poderá ser aplicado em outras populaçóes com características laborais semelhantes, já que a natureza do trabalho e a categoria profissional são homogêneas.

A observação não participante consistiu um total de $80 \mathrm{~h}$ e teve o foco em todos os trabalhadores e turnos de trabalho, realizada em dias e horários distintos, englobando todos os períodos. A observação seguiu um instrumento que buscou compreender o ambiente, os profissionais envolvidos, e os tópicos relacionados ao trabalho: condições, relações interpessoais, divisão, procedimentos executados, jornada, escala e horário, além disso, uso de monitoramento e equipamento individual, e a disponibilidades destes equipamentos e por último, avaliaçáo das atividades que contribuem para $o$ desgaste. As impressóes dos pesquisadores foram registradas em um diário de observação.

As entrevistas individuais aconteceram após o período de observação, com duração aproximada de uma hora, contou com a participação de todos os sujeitos e buscou-se compreender, sob o ponto de vista dos trabalhadores, os desgastes vivenciados e os impactos na saúde. Foi aplicado um roteiro pré-estruturado que buscou acessar as dimensôes visíveis e invisíveis, formais e informais do trabalho apreendido, a dualidade entre prazer e sofrimento, organização e condiçôes do trabalho, e também sobre práticas realizadas sob a ótica do prescrito e real. Por último, as entrevistas coletivas serviram para realizar a validação das primeiras impressões e constituírem novo material de pesquisa, gerando novas interpretaçóes o que conduziram para a saturação teórica dos dados.

Todas as entrevistas foram gravadas, transcritas e organizadas no software QualiQuantSoft ${ }^{\odot}$. Para análise utilizou-se o Discurso do Sujeito Coletivo (DSC), técnica onde diferentes depoimentos, com sentidos semelhantes, são reconstruídos de forma a representar um determinado grupo e/ ou coletivo ${ }^{(18)}$. Os resultados foram organizados em categorias que emergiram de acordo com a natureza dos desgastes manifestados nos discursos dos profissionais, oriundos das interaçóes das diferentes cargas de trabalho.

\section{RESULTADOS}

\section{Desgastes advindos das cargas de trabalho de} materialidade externa: As cargas de trabalhado se manifestam de acordo com a tarefa desempenhada, as circunstâncias que ela ocorre, as competências do trabalhador e sua percepção sobre o trabalho e sobre $\mathrm{si}^{(19)}$. As cargas de trabalho de materialidade externa são assim denominadas, pois podem ser evidenciadas sem envolver o trabalhador, elas são inerentes a atividade e irão interagir, durante a atividade laboral com o corpo desse profissional. Nos SMN observou-se a presença das cargas de trabalho de materialidade externa: biológicas, físicas, mecânicas e químicas.

As cargas biológicas correspondem à interação e exposição a agentes biológicos como bactérias, fungos e vírus. Trata-se de uma carga de trabalho inerente a natureza do trabalho da enfermagem, mas que pode desencadear importantes desgastes ao trabalhador. Nos SMN essa carga se apresenta no momento daassistência ao paciente, particularmente na realização da punção endovenosa para a injeção 
do radiofármaco o que foi constatado no período de observação e evidenciado no DSC 1:

"Preocupo-me com as doenças silenciosas como o HIV ou a hepatite C, mas não costumo usar luva, a fixação do acesso venoso é protocolo e isso é muito ruim de fazer com luvas. Já aconteceu acidente com material perfuro cortante. Sei que é errado, mas não consigo usar luvas. São vicios e precisamos assumir, não adianta justificar. É o hábito" (DSC 1).

O DSC 1 mostra que os profissionais reconhecem as cargas ao qual estáo expostos, porém isso é insuficiente para aderirem ao uso das luvas. Durante a observaçáo constatou-se que as cargas de trabalho se agregam, havendo a interação das cargas biológicas e das cargas físicas, aumentando os riscos de desgastes ao trabalhador. Essas condiçóes estáo relatadas no DSC 2:

"Durante a jornada de trabalho acontece de ter algum descuido e ao invés de colocar a seringa contaminada com radiação direto na lixeira de chumbo coloco em cima da bancada, sem nenhuma proteção por baixo. Já aconteceu de pegar a seringa com material radioativo sem luva. Sei que contamina, mas na correria isso acontece. Também acontece do paciente que já foi injetado passar mal, vomitar e urinar na maca e esse material acaba contaminando a nossa pele, roupas e sapato" (DSC 2).

Nos serviços pesquisados e no DSC 2 demonstrase uma fragilidade no domínio desse instrumento de trabalho, a radiação ionizante, realiza-se manejo fora do que prescreve a organização do trabalho ${ }^{(20)}$ e as normas ${ }^{(8)}$. Durante as observaçóes constatouse que os trabalhadores têm dúvidas quanto aos procedimentos de descontaminação e, pelo ritmo acelerado de trabalho, acabam não tomando as medidas necessárias. Os trabalhadores pesquisados admitem no DSC 3 que é necessário uma mudança de olhar sob o próprio trabalho, posto que não estão acostumados com o elemento da radiação ionizante no processo de trabalho da enfermagem:

"Acontece de estarmos com a seringa junto com o protetor de chumbo na mão e levantarmos a seringa... o pessoal da radiologia avisa para baixar. Para mim é normal uma seringa com medicaçâa levantada, $e$ ai lembro que tem material radioativo. A visão da enfermagem em medicina nuclear precisa mudar. $\dot{E}$ uma mudança de prática que não é fácil" (DSC 3).
O coletivo de trabalhadores relatou dificuldades em utilizar os equipamentos de proteção individual (EPIs) de chumbo, principalmente o avental. Notase no DSC 4 que os EPIs não são ergonômicos, o que desestimula o uso, evidenciando uma carga mecânica:

"Os EPIs de chumbo são dificeis de usar, são pesados, imagina usar o avental e protetor de tireoide durante 20 minutos administrando o material radioativo no paciente... atrapalha muito! Sinto dores muito fortes nos ombros e na regiäo lombar quando uso o avental de chumbo, ás vezes chego a pensar que a radiação não é tão prejudicial quanto esse avental" (DSC 4).

Durante a observação identificou-se que os aventais de chumbo não são confortáveis e limitam a atuação dos profissionais que precisam se curvar, às vezes se abaixar, conter pacientes e ainda, realizar a assistência com agilidade. Por outro lado, constatou-se uma maior adesão ao uso de protetores de tireoide. Além disso, as salas de preparo e injeção do radiofármaco são pequenas potencializando a carga mecânica, dificultando a movimentaçâo dos profissionais. O DSC 5 enfatiza a interação com essa carga:

"O espaço fisico é muito pequeno, atrapalha na realização do trabalho, pois você não consegue prestar uma assistência adequada. Se tem uma intercorrência é difícil agir, pois está tudo aglomerado com risco inclusive de acidentes" (DSC 5).

Ressalta-se ainda, que o serviço público não possui uma copa e/ou área de descanso para os trabalhadores, potencializando ainda mais os desgastes advindos das cargas mecânicas. Já as cargas químicas não foram valorizadas pelos profissionais em seus discursos, possivelmente pela normalidade da presença dessas cargas no cotidiano do trabalho da enfermagem. Durante a observaçáo identificouse as cargas químicas presentes na administração de medicamentos e no uso de produtos específicos para a descontaminaçáo de equipamentos e/ou superfícies.

Desgastes advindos das cargas de trabalho de materialidade interna: As cargas de trabalho de materialidade interna correspondem às cargas fisiológicas e cargas psíquicas, ambas manifestadas no trabalho dos serviços pesquisados. Essas cargas expressam-se diretamente no corpo do trabalhador, de forma a dificultar sua percepção externamente ${ }^{(19)}$. 
As cargas fisiológicas estão relacionadas aos sintomas físico do corpo ao executar o trabalho, dentre as quais se cita: levantamento de peso, postura inadequada, esforço físico e permanência de longos períodos em pé(21). Sendo que os trabalhadores em SMN são submetidos a grandes demandas de trabalho, executam suas atividades prioritariamente em pé durante toda a jornada e por vezes assumem posturas incorretas para cumprir com a finalidade da atividade; o DSC 6 enfatizam essa realidade:

"Trabalho muito, alguns dias não consigo parar nem para fazer xixi. Sinto dores no corpo, na coluna, tenho dor no punho e artrose. É dificil comprovar que você desenvolveu alguma doença por trabalhar com radiação, porém, os coletes de chumbo são muito pesados, somado a isso a posição e a altura para realizar a punção não são adequadas e as salas são muito pequenas. O chumbo que envolve a seringa com material radioativo também é pesado e precisamos carrega-lo várias vezes ao dia. As pernas ficam inchadas, a cabeça dói..." (DSC 6).

Observa-se a sobreposição das cargas de trabalho, trata-se de um ciclo onde uma carga de trabalho acaba por influenciar a manifestação de outras cargas, culminando em sérios desgastes. As cargas mecânicas oriundas do uso dos EPIs de chumbo se sobrepóem as condiçóes de trabalho, o que dão origem as cargas fisiológicas. No SMN a carga fisiológica é reconhecida pelos profissionais de enfermagem, mas pouco prevenida, na medida que incorporam essas situações desgastantes como inerentes ao trabalho realizado. Outrossim, um fator que se mostrou relevante no desgaste dos trabalhadores dos SMN advindos das cargas fisiológicas refere-se a dupla jornada, ou duplo vínculo. Nos serviços pesquisados metade dos trabalhadores possuem outro vínculo empregatício em enfermagem, como visto no DSC 7:

"Trabalhar em dois empregos é muito cansativo, alguns dias não consigo dormir, descanso apenas uma ou duas horas por dia. As pernas doem muito por ficar o dia inteiro em pé. Ao terminar o meu trabalho estou estressado, com dores nas pernas e até sem fome. Por isso, pela responsabilidade que tenho e o trabalho que desenvolvo a valorização salarial deveria ser melhor, tenho dois empregos, pois com um emprego náo consigo sustentar a minha familia" (DSC 7).

Em outra perspectiva, a radiação é um elemento gerador de estresse durante o processo de trabalho, propiciando desgastes mentais que se manifestam pelas cargas psíquicas. O DSC 8 demostra que a fragilidade no conhecimento sobre a radiação no SMN gera insegurança e preocupaçáo relacionada a probabilidade de desenvolverem doenças:

"Quando percebo passei 8 horas, recebendo radiação, isso cria uma preocupação, é todos os dias. Tenho medo de ficar doente futuramente, pois dizem que a radiação é cumulativa. Eu questiono o médico, mas ele diz que não tem como provar nada. Apesar da importância que a enfermagem tem na medicina nuclear a falta de conhecimento fragiliza o trabalho, tenho dificuldade com o EPI e sinto insegurança para tomar decisóes relacionadas à contaminação ou exposição" (DSC 8).

Outra situação que influencia a ação das cargas psíquicas é trabalhar com usuários portadores de câncer, doenças terminais ou com criança, conforme evidenciado no DSC 9:

"Cuidar de pacientes com câncer não é fácil, especialmente crianças, todos os dias sofro em ver o sofrimento do outro, às vezes até choro. Alguns dias estão mais estressado e passo ao menos 15 dias ruim, demoro a me recuperar, parece que não sou eu. Me sinto mal, com vontade de chorar, falo pouco... não me reconheço" (DSC 9).

O impacto das cargas de trabalho psíquicas advindas dessas situaçóes atinge diretamente o corpo do trabalhador, a ponto de desestabiliza-lo. As falas, durante as entrevistas, foram interrompidas algumas vezes por uma forte emoção e choro.

\section{DISCUSSÃO}

Os desgastes relatados pelos trabalhadores, oriundos das cargas de trabalho de materialidade externa, observados no DSC 1, evidencia a exposição a cargas biológicas, e a não utilização de luvas no exercício do trabalho. Entretanto, espera-se que o profissional da enfermagem utilize os equipamentos de proteção sempre que houver risco de transmissão de patógenos, como na manipulaçáo de sangue e fluídos corporais que poderão estar contaminados por agentes infecciosos ${ }^{(22)}$. No Brasil, entre 2010 e 2016 foram notificados 23.621 acidentes com material biológico entre os profissionais de saúde. $\mathrm{O}$ sangue foi o material biológico mais envolvido 
nos acidentes $(74,93 \%)$ por intervenção da via percutânea $(75,33 \%)$, com a agulha sendo o principal agente causador $(57,59 \%)$, e $29,71 \%$ dos pesquisados náo utilizavam luvas no momento do acidente $^{(23)}$. Já na Regiāo Sul do Brasil, de acordo com informaçóes do Instituto de Seguridade Social (INSS) entre os anos de 2013 a 2015 foram notificados 166 acidentes de trabalho envolvendo profissionais da enfermagem, destes, 32 aconteceram em Santa Catarina ${ }^{(24)}$.

O uso das luvas durante a assistência de enfermagem é importante para segurança do trabalhador e do usuário. É obrigatório sua utilização ao manipular materiais, sendo que após o uso deve ser descartada ${ }^{(25)}$. A responsabilidade pelo uso é compartilhada pela organização do trabalho ${ }^{(26)}$ e pelo próprio profissional que possui os saberes técnicos. Embora reconheçam a necessidade em utilizar as luvas no sentido de diminuir as cargas de trabalho biológicas e por consequência, o desgaste advindo $\mathrm{da}$ atividade laboral, os trabalhadores nos serviços pesquisados associam o não uso pela falta de hábito.

No DSC 2 é notória a preocupação frente ao risco físico da contaminaçáo pelo material radioativo oriundo do paciente. Isto ocorre porque após a injeção do radiofármaco o paciente passa a ser a fonte da exposição a radiação e existe a possibilidade dos fluídos por ele excretados se apresentar como uma fonte de exposição a radiação ionizante ${ }^{(10)}$. A exposição do trabalhador a estas situaçóes pode trazer implicaçóes à sua saúde, que poderão repercutir diretamente na sua vida financeira, social e familiar, na situação de haver um afastamento em virtude de algum acidente com material biológico contaminado $^{(22)}$.

O DSC 3 comprova a necessidade de mudanças da prática de trabalho no SMN dos profissionais da enfermagem. $O$ instrumento de trabalho desta equipe difere-se do instrumento comumente utilizado no ambiente hospitalar e exige o uso de EPIs distintos. Todavia, o uso dos EPIs nos serviços pesquisados representa uma carga de trabalho importante para os profissionais, a carga mecânica. Estas são responsáveis por provocar desgastes manifestados em lesóes que podem inclusive incapacita-lo ${ }^{(10-12)}$.

No geral, os aventais de chumbo possuem alto peso atômico, sáo confeccionados de chumbo e borracha e reduzem a radiação em até $90 \%{ }^{(27)}$. O uso do avental colabora com a saúde do trabalhador, entretanto retrata o desgaste por dores lombares e articulares, advindas do uso da vestimenta de proteçáo por tempo prolongado ${ }^{(27,28)}$. Observouse adesão ao uso do protetor de tireoide fato que pode estar relacionado ao menor tamanho e peso do material, bem como trata-se de uma regiáo que não restringe as habilidades corporais no momento da assistência. Ademais, os serviços pesquisados realizam o tratamento do câncer de tireoide por iodoterapia e o contato constante com pacientes afetados por esse tipo de câncer pode servir como sensibilizador para o uso do EPI. Ainda sobre o carga mecânica, o DSC 5 aponta os ambientes físicos impróprios para o trabalho. A adequação ergonômica dos ambientes se fazem necessárias em especial para prevenir e reduzir os desgastes, essas ações devem ser elaboradas pela organização do trabalho em conjunto com os profissionais a fim de contribuir para as condiçóes de saúde do indivíduo $^{(12)}$. O espaço limitado representa uma ameaça na ocorrência de acidentes de trabalho, percebe-se que as açóes de conforto e cuidados dos pacientes ficam limitadas pelas condiçôes físicas o que, para os trabalhadores limitam um bom atendimento. Quando o ambiente de trabalho é insatisfatório os desgastes psicológicos podem aumentar $^{(29)}$.

A segunda categoria de análise supracitada descreve os desgastes dos trabalhadores em SMN advindos das cargas de materialidade interna, aquelas que materializam-se no corpo do trabalhador, que correspondem a transformações nos processos interiores ${ }^{(5)}$. O cotidiano do trabalho da enfermagem é permeado por demanda de esforço físico, elevação de peso, e limitaçóes físicas nos ambientes, estes aspectos refletem em posturas inadequadas, fadiga e estresse. O DSC 6 indica estes desgastes, ratificando o discurso, estudo ${ }^{(30)}$ relaciona dor lombar inespecífica dos profissionais da enfermagem com as condições e organização do trabalho, tais como tarefas repetitivas, ritmo de trabalho excessivo, e ambiente físico de trabalho inadequado. Destaca-se que estas condiçôes entre os profissionais reflete diretamente na capacidade para o trabalho, por isso sugere-se que os níveis de fadiga sejam monitorados a fim de prevenir efeitos deletérios a longo prazo ${ }^{(31)}$.

O DSC 7 aponta a realidade dos profissionais possuírem dupla jornada de trabalho, sendo os fatores econômicos os principais motivos para tal ${ }^{(32)}$. 
A valorização salarial surge como um mecanismo de motivação para superar as dificuldades e fragilidades encontradas no trabalho, o trabalhador sujeitandose a essas condiçóes acaba por potencializar as situaçóes geradoras de desgaste ${ }^{(13)}$. Altos níveis de fadiga, conforme relatado pelos DSC 6 e 7, estão diretamente relacionados com o aumento na probabilidade de erros durante a assistência ao paciente $^{(33)}$. Destaca-se ainda que a sobrecarga de trabalho, advindas do duplo vínculo, reflete na saúde do profissional, havendo insatisfação com o trabalho e consequentemente o indivíduo fica mais propenso ao sofrimento psíquico, o que pode prejudicar o desempenho profissional e a qualidade da assistência prestada ao paciente ${ }^{(34)}$.

Em relação a preocupação descrita pelo DSC 8 , Dejours ${ }^{(2)}$ afirma que esta é desenvolvida principalmente por trabalhadores que possuem pouca formação ou conhecimento sobre a tarefa que será executada, já que geralmente, essas habilidades são conquistadas ao longo da experiência no trabalho. O autor associa a preocupação à interação das cargas de trabalho que progressivamente vão conduzindo os trabalhadores ao esgotamento e desgastes. Além disso, o medo representa uma importante fonte de desgaste, já que o medo é parte integrante da carga de trabalho psíquica, seja ele proveniente do ritmo ou das condiçóes de trabalho ${ }^{(2)}$. As cargas psíquicas influenciam negativamente no nível de satisfação do profissional da enfermagem ${ }^{(35)}$. Finalizando essa categoria, o relato do DSC 9 revela as cargas psíquicas vivenciados no atendimento do paciente oncológico, o fato corrobora com estudo que relaciona as cargas de trabalho na assistência oncológica com a ansiedade e depressão ${ }^{(36)}$, ou ainda desgaste emocional e baixa realização pessoal em seu trabalho ${ }^{(35)}$. Tal fato revela a importância do trabalhador receber preparo para lidar com as situaçóes de dor e sofrimento do outro, além de apoio e acompanhamento psicológico.

Baseado no tamanho da amostra e no estudo regional em apenas dois serviços identifica-se a limitação relacionada à característica regional, de modo que pesquisas futuras possam abranger mais estados com vistas a confrontar os resultados obtidos. Aponta-se também como limitação a dificuldade em atribuir o nexo causal da carga de trabalho física em relação a exposição à radiação ionizante aos prováveis desgastes vivenciados pelos trabalhadores da enfermagem.

\section{CONCLUSÓES}

O trabalho da enfermagem em SMN é complexo e cercado de diferentes cargas de trabalho, principalmente a carga física da radiação ionizante. Observou-se uma sobreposição das cargas de trabalho proporcionais as demandas da organização entre elas as cargas mecânica, biológica, química, fisiológica e psíquica. As cargas física, fisiológica e psíquica estão relacionadas a especificidades do processo de trabalho e manifestam-se principalmente quanto ao uso da radiação ionizante, utilização de equipamentos de proteção individuais, medo e ansiedade gerados pelo trabalho com a radiação.

Os desgastes manifestados pelos profissionais pesquisados impactam no corpo do trabalhador de duas formas, por meio de manifestações físicas e de desgastes psíquicos estes mais difíceis de identificar. É importante salientar que a sobrecarga física acaba por gerar também desgaste psíquico, levando ao cansaço extremo. Os desgastes incapacitam o trabalhador e podem levar ao afastamento temporário ou permanente do trabalho o que causa contratempos, não somente a vida íntima e familiar do trabalhador, como impacta diretamente na organização e acaba por onerar os sistemas de saúde em função das internaçóes, medicamentos e tratamentos.

A enfermagem, enquanto categoria deve se empoderar de forma mais assertiva dessa especialidade, uma vez que se trata de uma área de atuação carente de regulação e de capacitação. Por isso, a educação continuada e pesquisas sobre essa temática são essenciais para um processo de trabalho menos desgastante, além do reconhecimento por parte dos trabalhadores e da organização das cargas de trabalho dessa especialidade.

O estudo possibilitou a interface de conhecimento por pesquisadores de categorias profissionais distintas -técnica radiológica e enfermagemproporcionando um distanciamento entre os sujeitos da pesquisa e, por consequência, análise dos dados com menos vieses. 


\section{REFERÊNCIAS}

1. Marques VP. O capitalismo flexível e a saúde do trabalhador: novos paradigmas e o problema da efetividade do direito [Internet]. 2017 [cited 2020 nov 6]; 59-79. Disponível em: http://site.fdv.br/ wp-content/uploads/2017/03/04-O-capitalismoflexi\%CC\% 81 vel-e-a-sau \% CC $\% 81$ de-dotrabalhador-Vinicius-Marques.pdf

2. Dejours C. A loucura do trabalho: Estudo de psicopatologia do trabalho. 6th ed. São Paulo: Cortez; 2015. 224 p.

3. Felli VEA, Baptista PCP. O contexto do trabalho de enfermagem e a saúde do trabalhador. In Felli VA, Baptista PCP. Saúde do trabalhador de enfermagem. Barueri: Manole; 2015:1-19.

4. De Carvalho DP, Rocha LP, Barlem JGT, Dias JS, Schallenberger CD. Cargas de trabalho e a saúde do trabalhador de enfermagem: revisão integrativa. Cogitare Enferm [Internet]. 2017 Mar 01 [citado 2020 nov 6]; 22(1): 01-11. Disponível em: https:// revistas.ufpr.br/cogitare/article/view/46569

5. Prudente JAB, Salum NCh, Gelbcke FL, Lorenzetti J, Schier J. O desgaste de trabalhadores de enfermagem no cuidado a pacientes oncohematológicos hospitalizados. Cogitare Enferm [Internet]. 2015 [citado 2020 nov 6]; 20(1): 208. Disponível em: http://dx.doi.org/10.5380/ ce.v20i1.38299

6. Sapienza MT, Willegaignon J. Radionuclide therapy: current status and prospects for internal dosimetry in individualized therapeutic planning. Clinics [Internet]. 2019 [citado 2020 oct 29]; 74: e835. Disponível em: http://dx.doi.org/10.6061/ clinics/2019/e835

7. Ge J, Zhang Q, Zeng J, Gu Z, Gao M. Radiolabeling nanomaterials for multimodality imaging: New insights into nuclear medicine and cancer diagnosis. Biomaterials [Internet]. 2019 Oct 22 [citado 2020 oct 29]; 228(119553): 1-25. Disponível em: https://doi.org/10.1016/j. biomaterials.2019.119553

8. Brasil. Comissão Nacional de Energia Nuclear. Requisitos de segurança e proteçáo radiológica para serviços de medicina nuclear [Internet]; 2013 [citado 2020 oct 29]. Disponível em: http://appasp. cnen.gov.br/seguranca/normas/pdf/Nrm305.pdf

9. Alotaibi M, Al-Abdulsalam A, Bakir YY, Mohammed AM. Radiation awareness among nurses in nuclear medicine departments. Aust J Adv Nurs [Internet]. 2015 May 01 [cited 2020 oct 29]; 32(3): 25-33. Disponível em: https://www.ajan. com.au/archive/Vol32/Issue3/3Alotaibi.pdf

10. Melo JAC, Gelbcke FL, Huhn A, Viana E. Nursing workloads in nuclear medicine. J of Nurs
UFPE on line [Internet]. 2017 [citado 2020 oct 29]; 11(3): 1279-1288. Disponível em: https:// www.researchgate.net/publication/314243857_ nursing_workloads_in_nuclear_medicine

11. Baptista PCP, Tito RS, Carvalho MB. A exposiçáa às cargas psíquicas e os processos de desgaste em trabalhadores de enfermagem. Saúde do trabalhador de enfermagem. Barueri (SP): Manole; 2015. p. 189-203.

12. Costa TF, Guimarães ALO, Felli VEA. A exposição dos trabalhadores de enfermagem às cargas mecânicas. In: Felli VE, Baptista PCP. Saúde do Trabalhador de Enfermagem. Barueri: Manole; 2015. p. 102-129.

13. Dalri RCMB, Silva LA, Mendes AMOC, Robazzi MLCC. Nurses' workload and its relation with physiological stress reactions. Rev Latino-Am Enfermagem [Internet]. 2014 Dec [citado 2020 nov 6]; 22(6): 959-965. Disponível em: https:// doi.org/10.1590/0104-1169.3292.2503

14. Laurell AC, Noriega M. Processo de Produção e Saúde: Trabalho e Desgaste Operário. Sáo Paulo: Hucitec; 1989.333 p.

15. Flôr RC, Melo JAC, Gelbcke FL, Ramos FRS, Amadigi FR. Investigaçấo da práxis em enfermagem radiológica: aplicação da metodologia da psicodinâmica do trabalho. Texto contextoenferm [Internet]. 2017 [citado 2020 nov 6]; 26(3): e0930017. Disponível em: https://doi. org/10.1590/0104-07072017000930017

16. Mendes AM, Araujo LKR. Clínica Psicodinâmica do Trabalho: o sujeito em ação. Curitiba: Juruá; 2012. 156 p.

17. Brasil. Governo do Estado de Santa Catarina. Sistema de Informação Estadual de Radiaçôes Ionizantes: Secretaria do Estado da Saúde [Internet]. 2018 [citado 06 nov. 2020]. Disponível em: http://www.sieri.saude.sc.gov.br/sieri/

18. Lefevre F, Lefevre AMC. Discourse of the collective subject: social representations and communication interventions. Texto contextoenferm [Internet]. 2014 Jun [citado 2020 mai 22]; 23(2): 502-507. Disponível em: http://www.scielo. br/scielo.php?script =sci_arttext $\&$ pid $=$ S010407072014000200502\&lng=en.

19. Martins JT, Ribeiro RP, Bobroff MCC, Marziale MHP, Robazzi MLCC, Mendes AC. Significado de cargas no trabalho sob a ótica de operacionais de limpeza. Acta paul enferm [Internet]. 2013 [citado 2020 nov 6]; 26(1): 63-70. Disponível em: https:// doi.org/10.1590/S0103-21002013000100011.

20. Bwanga O. Nurses' knowledge of radiation protection in medicine: a review of literature. Prof Nurs Today [Internet]. 2020 Oct 10 [citado 2020 nov 6]; 24(3): 1-3. Disponível em: http://pntonline. 
co.za/index.php/PNT/article/view/1056.

21. Carvalho DP, Rocha LP, Pinho EC, TomaschewskiBarlem JG, Barlem ELD, Goulart LS. Cargas de trabalho e os desgastes à saúde dos trabalhadores da enfermagem. Rev Bras Enferm [Internet]. 2019 Dec [citado 2020 nov 6]; 72(6): 1435-1441. Disponível em: https://doi.org/10.1590/00347167-2017-0659.

22. Brown L, Munro J, Rogers S. Use of personal protective equipment in nursing practice. Nurs Stand [Internet]. 2019 Apr 26 [citado 2020 oct 29]; 34(5): 9-66. Disponível em: https://pubmed. ncbi.nlm.nih.gov/31468815/.

23. Gomes SCS, Caldas ADJM. Incidência de acidentes de trabalho com exposição a material biológico em profissionais de saúde no Brasil, 2010-2016. Rev Bras Med Trab [Internet]. 2019 Jun 04 [citado 2020 nov 6]; 17(2): 188-200. Disponível em: http://www.rbmt.org.br/about-the-authors/450/ $\mathrm{pt}-\mathrm{BR}$

24. Brasil. Ministério da Fazenda. Anuário estatístico de acidentes do trabalho: AEAT 2015 [Internet]. 2015 [citado 2020 nov 6]. Disponível em: http:// sa.previdencia.gov.br/site/2017/05/aeat15.pdf

25. Ohnuki K, Yoshimoto M, Fujii H. Radiological protection and biological COVID-19 protection in the nuclear medicine department. Eur J Nucl Med Mol Imaging [Internet]. 2020 Oct 10 [citado 2020 nov 6]; 47(11): 1-3. Disponível em: https:// doi.org/10.1007/s00259-020-05062-9.

26. Brasil. Norma Regulamentadora 6: Equipamento de Proteção Individual [Internet]. 2018 Oct 26 [citado 2020 nov 6]. Disponível em: https://enit. trabalho.gov.br/portal/images/Arquivos_SST/ SST_NR/NR-06.pdf

27. Pereira AG, Vergara LGL. Aspectos Ergonômicos da Vestimenta de Proteçáo Radiológica. In: X Congreso Regional Latinoamericano Irpa de Protección y Seguridad Radiológica, 2015 [Internet]. 2015 Apr [citado 2020 oct 29]. Disponível em: researchgate. net/publication/275214464_Aspectos_ ergonomicos_da_vestimenta_de_protecao_ radiologica

28. Flôr RC, Gelbcke FL, Huhn A. Equipamento de Proteção Radiológica e o desgaste do trabalhador. In: Latin American Irpa Regional Congress On Radiation Protection And Safety [internet]; Rio de Janeiro: Sociedade Brasileira de Proteção Radiológica; 2013. p.1-8. [citado 2020 oct 29]. Disponível em: http://www.sbpr.org.br/old/web/ irpa13/AnaisdoIRPA2013/Radioprotecciondel pacientetrabajadoresmiembrosdelpublicoymedio ambiente/3696.pdf

29. Ceballos-Vásquez P, Solorza-Aburto J, Marín-Rosas N, Moraga J, Gómez-Aguilera N, Segura-Arriagada $\mathrm{F}$ et al. Estrés percibido en trabajadores de atención primaria. Cienc enferm [Internet]. 2019 [citado 2020 nov 6]; 25:5. Disponível em: http://dx.doi. org/10.4067/s0717-95532019000100204.

30. Cargnin ZA, Schneider DG, Vargas MAO, Machado RR. Non-specific low back pain and its relation to the nursing work process. Rev Lat-Am Enfermagem [Internet]. 2019 Oct 07 [citado 2020 oct 29]; 27: 1-10. Disponível em: https://www. ncbi.nlm.nih.gov/pmc/articles/PMC6781409/.

31. Silva TPD, Araújo WN, Stival MM, Toledo AM, Burke TN, Carregaro RL. Desconforto musculoesquelético, capacidade de trabalho e fadiga em profissionais da enfermagem que atuam em ambiente hospitalar. Rev esc enferm USP [Internet]. 2018 [citado 2020 nov 06]; 52: e03332. Disponível em: http://dx.doi.org/10.1590/s1980220x2017022903332.

32. Brey C. O absenteísmo entre os trabalhadores de saúde de um hospital público do sul do Brasil. RECOM [Internet]. 2017 Mar 23 [citado 2020 nov 6]; 7(1): 1-10. Disponível em: https://doi. org/10.19175/recom.v7i0.1135.

33. Jones G, Hocine M, Salomon J, Dab W, Temime L. Demographic and occupational predictors of stress and fatigue in French intensive-care registered nurses and nurses' aides: a cross-sectional study. Int J Nurs Stud [Internet]. 2015 Jan 02 [citado 2020 oct 29]; 52(1): 250-259. Disponível em: https:// pubmed.ncbi.nlm.nih.gov/25443305/.

34. Maharaj S, Lees T, Lal S. Prevalence and Risk Factors of Depression, Anxiety, and Stress in a Cohort of Australian Nurses. Int J Environ Res Public Health [Internet]. 2018 Dec 27 [citado 2020 oct 29]; 16(1): 2-10. Disponível em: https://www. ncbi.nlm.nih.gov/pmc/articles/PMC6339147/.

35. Soto FPE, Barrios AS, Molina MY. Burnout syndrome and labor satisfaction as predictors of quality of the hospital nursing attention. Cienc enferm [Internet]. 2017 Dec [citado 2020 nov 6]; 23(3): 99-111. Disponível em: http://dx.doi. org/10.4067/S0717-95532017000300099.

36. Keskin Ö, Oktay E, Turan M, Kertmen N, Tanriverdi O, Imamoglu GI, et al. Depression and anxiety in oncology nurses. J Clin Oncol [Internet]. 2018 Jun 01 [citado 2020 oct 29]; 36(15): e18552. Disponível em: https://ascopubs. org/doi/abs/10.1200/JCO.2018.36.15_suppl. e18552 